Non-Hodgkin lymphoma (NHL) is a common disease, but primary lymphoma of the prostate is rare.

Material and methods: Here we present two cases of primary NHL of the prostate and a review of the relevant literature. Results: Both of them had no abnormal lymph node or hepatolienal enlargement. The first case underwent prostatic biopsy which indicated that it was NHL The patient underwent combination chemotherapy three times, then a radical cystoprostatectomy. In the second case, the prostatic biopsy was not helpful for diagnosis. Therefore a radical prostatectomy was performed before the proper chemotherapy been given. He died half a year later because of a cerebrovascular accident.

Conclusions: We think it is difficult to get an accurate early diagnosis when the lymphoma occurs only in the prostate. Even the prostatic biopsy could not provide clear evidence. Early and appropriate treatment can extend the survival time and improve the quality of life.

Key words: non-Hodgkin lymphoma, prostatic neoplasms, needle biopsy, diagnosis.

\section{Primary lymphomas of the prostate: two case reports and a review of the literature}

\author{
Chaojun Wang ${ }^{1}$, Peng Jiang ${ }^{1}$, Jun $\mathrm{Li}^{2}$
}

1Department of Urology, First Affiliated Hospital, College of Medicine, Zhejiang University, HangZhou City, Zheliang Province, PR China

2Department of Pathology, First Affiliated Hospital, College of Medicine, Zhejiang University, HangZhou City, ZheJiang Province, PR China

\section{Introduction}

Non-Hodgkin lymphoma (NHL) is a common disease and about one third of cases occur in extranodal sites. Primary lymphoma of the prostate is rare; it comprises about $0.1 \%$ of all NHLs and $0.09 \%$ of all prostatic malignancies [1]. Diagnosis of primary lymphomas in the prostate must combine the patient's symptoms, computed tomography (CT), magnetic resonance imaging (MRI) and pathology examination. We present two cases of primary NHL of the prostate and a review of the literature.

\section{Case reports}

\section{Case 1}

A 61-year-old man was hospitalized because of pain of the lower abdominal region and the left abdominal wall lasting about two months. He also had dysuria and a weak urinary stream. Digital rectal examination (DRE) showed a hard and voluminous prostate; the edge of the prostate was not clearly defined. Neither abnormality of lymph node nor enlargement of liver and spleen could be found by general examination.

The prostate-specific antigen (PSA) value was $2.3 \mathrm{ng} / \mathrm{ml}$, Hb was $10.9 \mathrm{~g} / \mathrm{dl}$ and WBC $7.9 \times 10^{3} / \mathrm{L}$ (neutrophils $73.6 \%$, lymphocytes $13.6 \%$, monocytes $6.8 \%$ ). Routine ultrasound of the urinary tract showed uretero-hydronephrosis on the left side. A huge occupation, also to the left of the prostate, was measured at $9.7 \times 7.5 \times 6.7 \mathrm{~cm}$. Urinary tract radiography examination showed delayed visualization and hydronephrosis in the left kidney and ureter. The pelvic and the kidney CT scan showed evidence of a huge expanded and infiltrative lesion of the prostate which involved the bladder neck. Bone scintigraphy was negative and did not show any other lesions. Prostate biopsy was performed according to the CT scan. The histology examination identified the diagnosis of $\mathrm{NHL}$ in the prostate. The patient underwent chemotherapy with cyclophosphamide $\left(750 \mathrm{mg} / \mathrm{m}^{2} / \mathrm{d}\right)$, vincristine $\left(1.4 \mathrm{mg} / \mathrm{m}^{2} / \mathrm{d}\right)$, doxorubicin $(50 \mathrm{mg} / \mathrm{d})$, prednisone $\left(60 \mathrm{mg} / \mathrm{m}^{2} / \mathrm{d}\right)$ and etoposide $\left(100 \mathrm{mg} / \mathrm{m}^{2} / \mathrm{d}\right)$ three times. The clinical result suggested a significant improvement after one cycle. The pain symptoms had disappeared, micturition improved and the ureter-hydronephrosis was decreased. Transrectal ultrasound (TRUS) examination showed the size of the prostate to be decreased from 234 to $203 \mathrm{ml}$. To decrease the possibility of recurrence, radical cystoprostatectomy and ileal bladder was performed three months later.

Macroscopically, the tumor was less elastic, measuring $9.7 \mathrm{~cm}$ in the maximal dimension. The cut surface of the tumor was gray-white, with areas of necrosis. Histological examination of the tumor revealed that the normal prostatic tissues were diffusely infiltrated by large lymphoid cells, with vesicu- 
lar nuclei, fine chromatin and scanty cytoplasm, either amphophilic or basophilic (Fig. 1). Immunohistochemically, the tumor cells were strongly positive for CD45, CD20, CD79a and negative for CD10, CD5, CD23, CD3, CD45RO, PSA, P504S, 34ßE12, CKpan, Syn and CgA (Fig. 2). The pathological examination confirmed the diagnosis of a primary NHL (diffuse large B-cell type) of the prostate.

\section{Case 2}

A 56-year-old man presented with dysuria in the form of urgency lasting for 2 weeks. He had no fever, no abdominal pain or any other complaint. General physical examination was unremarkable. DRE revealed an enlarged indurate prostate. The surface was tuberous and irregular. The central groove was disappeared. PSA was $0.328 \mathrm{ng} / \mathrm{ml}$ and TRUS of the urinary tract showed that the prostate volume was $233 \mathrm{ml}(8.4 \times 7.2 \times 7.7 \mathrm{~cm})$. The pelvic CT showed lack of prostate capsule integrity and that the tumor had invaded the seminal vesicle. Bone scintigraphy was negative. No evidence of tumor in other anatomical locations was found. The biopsy sample indicated that it was a malignant tumor but it could not be stated with certainty which kind. The tumor was located in the prostate without bladder infiltration. Therefore we performed a radical prostatectomy. Macroscopically, the tumor tissues were fragmentized and the cut surface was gray-white and elastically soft. Histologically, the tumor was composed of large atypical cells with vesicular nuclei, abundant cytoplasm, and a high mitotic rate. It had a diffuse infiltrating pattern (Fig. 3). A few entrapped prostate gland cells were seen within the tumor. In immunohistochemistry, CD45, CD20, CD79a were positive in tumor cells while CD10, CD5, CD23, CD3, CD45RO, PSA, P504S, 34ßE12, CKpan, Syn and CgA were negative (Fig. 4). Pathologic examination confirmed the diagnosis of primary NHL (diffuse large B-cell type) of the prostate.

The patient was postoperatively treated with combined chemotherapy using rituximab $\left(375 \mathrm{mg} / \mathrm{m}^{2} / \mathrm{d}\right)$, cyclophos phamide $\left(750 \mathrm{mg} / \mathrm{m}^{2} / \mathrm{d}\right)$, vincristine $\left(1.4 \mathrm{mg} / \mathrm{m}^{2} / \mathrm{d}\right)$, dox-

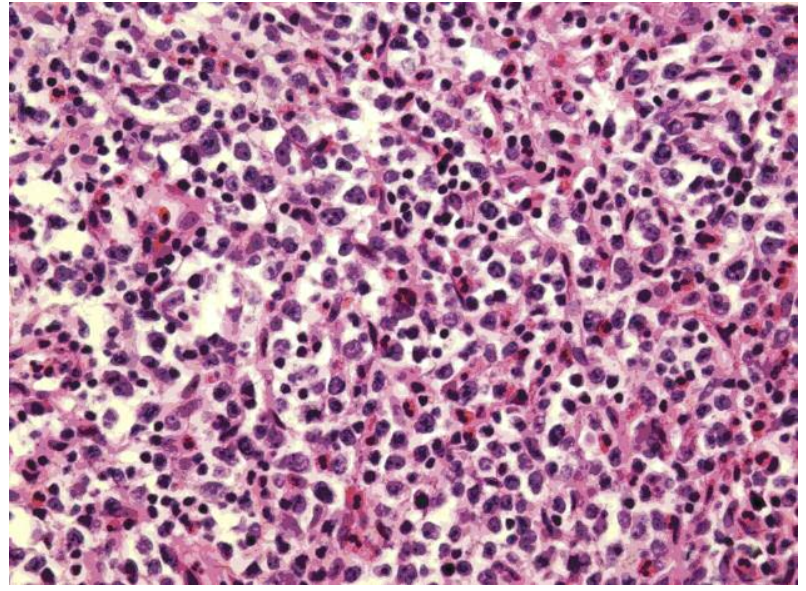

Fig. 1. This histological feature reveals that the normal prostatic tissues have been replaced by diffusely infiltrated large lymphoid cells. $H \& E \times 400$

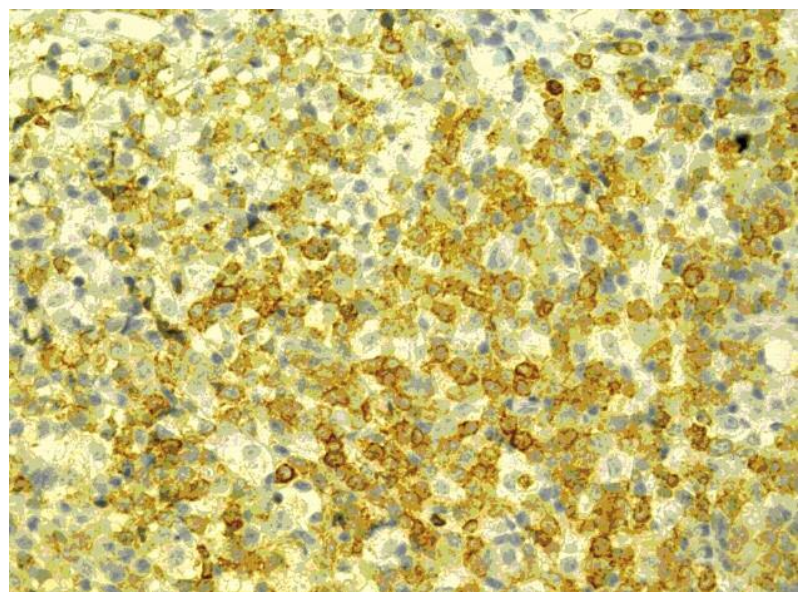

Fig. 2. Immunohistochemistry showed the tumor cells to be positive for CD45, CD20, CD79a. DAB ×400

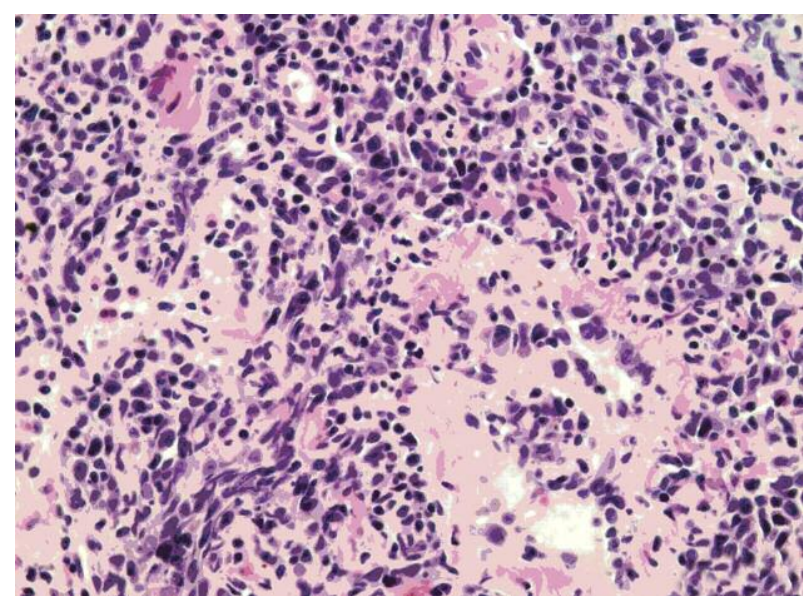

Fig. 3. The tumor was composed of large atypical cells with vesicular nuclei and abundant cytoplasm, H\&E $\times 400$

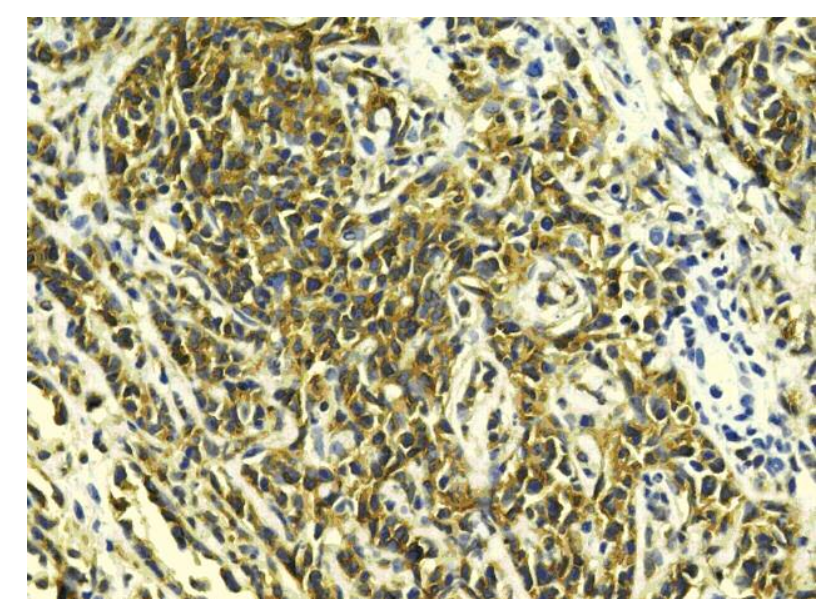

Fig. 4. Immunohistochemistry showed that the tumor cells were positive for CD45, CD20, CD79a, DAB $\times 400$ 
orubicin $(50 \mathrm{mg} / \mathrm{d})$, prednisone $\left(60 \mathrm{mg} / \mathrm{m}^{2} / \mathrm{d}\right.$ ) and etoposide $\left(100 \mathrm{mg} / \mathrm{m}^{2} / \mathrm{d}\right)$ three times. The disease remitted after treatment, but the patient died half a year later due to cerebrovascular accident.

\section{Discussion}

The definition of primary lymphoma of the prostate must be consistent with three criteria, recommended by Bostwick and Mann: 1) presenting symptoms attributable to prostatic enlargement; 2) involvement of the prostate predominantly, with or without involvement of adjacent tissue; and 3) absence of involvement of the liver, spleen or lymph nodes within one month of diagnosis of the prostatic involvement [2]. Some investigators suspected the existence of primary extranodal prostatic lymphoma because of the deficiency of lymphoid tissue in the prostate, while others believe the primary lymphoma in the prostate to be due to rudimentary lymphoid nodules and extramedullary hematopoiesis in the prostate. The patient's clinical histological documentation shows that the disease is limited in the prostate without retroperitoneal lymph node involvement [3]. It can happen at any age between 18 and 89 years old and the means is 57 years old [4].

There are no systemic symptoms of this disease. Frequency and urgency may be the most common symptoms and hematuria sometimes is an early presenting symptom. It is very difficult to distinguish from other prostate diseases, such as prostate carcinoma or nodular hyperplasia, because all of these diseases can cause lower urinary tract obstruction. It often shows diffusely enlarged, non-tender, firm or rubbery consistency and obliteration of the median sulcus when examined by DRE. Though the prostate is hard, it is usually not as hard as the typical prostate carcinoma [5, 6]. The serum acid phosphatase value and PSA in general are usually within the normal range, but Tomaru et al. reported on an 84-year-old patient, diagnosed with a primary low-grade B-cell lymphoma of the prostate, who had a very high PSA (903 ng/ml). The PSA decreased to $8.6 \mathrm{ng} / \mathrm{ml}$ three months after transurethral resection of the prostate (TURP) [7]. Oosterheert et al. recently reported on another follicular $\mathrm{NHL}$ of the prostate which had high levels of serum PSA $(62 \mathrm{ng} / \mathrm{ml})$. The PSA decreased to the normal level after lymphoma-specific treatment [8].

Rainwater and Barrett have described hypoechoic appearance of prostatic lymphoma during TRUS because the prostatic lymphoma destroys the normal prostatic architecture, replacing it with malignant cells without glandular structure [9]. However, Terris et al. suggested that the lower echogenicity associated with the inflammatory lymphocytic infiltrate and prostate cancer might be caused by the echotexture of the glands and the periglandular area rather than the abnormal cellularity within the stroma of the prostate [10]. The CT and MRI scan appearance is non-specific, but may help to evaluate the stage.

Almost all reported cases could not be diagnosed correctly before the tissue sections were examined. But the sensitivity of TRUS guided prostate needle biopsy is lower (only 22.2\%) for detecting hematolymphoid malignancies involving the prostate because prostatic infiltration by malignant lym- phocytes is irregular [10]. For a pathologist the most difficult situation to obtain an accurate histological diagnosis is highly undifferentiated NHL occurring only in the prostate, without any other evidence, or any other tissue involved in another part of the body [5, 11]. Differential diagnosis includes prostatitis, prostate cyst or abscess, small cell carcinoma, lymphoepithelioma-like carcinoma and Hodgkin lymphoma ( $\mathrm{HL})$. Sometimes doctors must be aware of existing neoplasms originating from seminal vesicles and Mullerian duct relics.

Another two rare diseases must be considered when the final diagnosis can be made according to the histopathology, immunophenotypic or molecular technique. One is coexisting lymphoma and adenocarcinoma in the same prostate [12]; the other is prostatic infiltration by leukemic cells [13]. All types of lymphoma have been described. They are chronic lymphocytic leukemia, diffuse centroblastic/centrocytic, small lymphocytic lymphoma, diffuse small-cleaved cell, diffuse mixed small and large cell, diffuse large cell, Burkitt's small non-cleaved cell, non-Burkitt, lymphoblastic and monocytoid B-cell lymphoma, while diffuse large B-cell lymphoma is the most common one $[4,5,14]$.

$\mathrm{NHL}$ of the prostate sometimes may co-exist with prostate adenocarcinoma $[2,15,16]$. Ballario et al. reported a patient who had urinary obstructive symptoms with an enlarged prostate after TURP [12]. The pathological examination showed an adenocarcinoma with $5 \%$ of the tissue material associated with infiltration of low-grade $\mathrm{NHL}$. Another situation which should be paid more attention is prostate carcinoma sometimes mimicking malignant lymphoma, especially when it presents with generalized lymphadenopathy [17]. Lymph node involvement in prostate carcinoma may be present in $8-20 \%$ of stage B and $40-80 \%$ of stage $C$ patients with negative bone studies. Prostate carcinoma sometimes metastasizes to the lymph nodes earlier than skeletal metastases, which may lead to misdiagnosis as lymphoma before the lymph biopsy [18]. It is difficult to distinguish them because a small percentage of high-grade prostatic carcinomas cannot be stained due to the absence of PSA, even though biopsy samples are used [19].

There are many therapeutic methods including chemotherapy, radiotherapy and surgical operations. Before treatment of patients, the tumor should be precisely categorized according to certain guidelines, such as patient's age, tumor bulk, clinical stage and histological classification. Accurate staging can be achieved exactly if the tumor is distant or shows regional dissemination to nodal sites or to bone marrow [15]. Chemotherapy is suitable for high-grade tumors, bulky tumors and disseminated disease. Aggressive regional therapy such as transurethral or segmental resection followed by radical radiotherapy to the whole pelvis may benefit small and localized lower grade tumors [20]. Though surgery and radiotherapy will not get the best results they can relieve the distressing symptoms of bladder outlet obstruction [2]. One of our patients underwent cystoprostatectomy because the disease was infiltrated into the bladder neck and orifice of the left ureter, causing some obstruction symptoms. Another had radical prostatectomy because the first biopsy sample was misdiagnosed as prostate cancer. The question of which operation can be done 
and may be beneficial to patients should be critically discussed. The operation indications depend on local findings and the prognosis of the patients and there are no standard operation methods to treat prostate NHL.

The extent of this disease at the diagnosis is the most important prognostic factor and is affected by two factors: 1) stage and bulk of the disease at diagnosis; 2) the tumor's histological classification. Tumor categories of low, intermediate or high grade correlate well with prognosis [20]. The prognosis is generally very poor because at the time that diagnosis is established, $40-50 \%$ of these patients have presented with metastasis [11]. Bostwick et al. found that the average survival period is 14 months and most patients died within two years [2].

Early diagnosis depends on the doctors' awareness of this disease, especially in young and middle-aged men who have a refractory "prostatitis" which does not respond to any antibiotic therapy. DRE shows a soft, enlarged prostate similar to a prostate abscess which is encountered on rectal examination. Early and appropriate treatment can extend the survival time and improve the quality of life.

The authors declare no conflict of interest.

\section{References}

1. Antunes AA, Dall'Oglio M, Srougi M. Primary lymphoma of the prostate: a rare case of urinary obstruction. Int Braz J Urol 2004; 30 410-2.

2. Bostwick DG, Mann RB. Malignant lymphomas involving the prostate. A study of 13 cases. Cancer 1985; 56: 2932-8.

3. Humphrey PA, Vollmer RT. Extramedullary hematopoiesis in the prostate. Am J Surg Pathol 1991; 15: 486-90.

4. Judith AF, Robert HY. Malignant lymphoma of the genitourinary tract. Current Diagnostic Pathology 1997; 4: 145-69.

5. Bostwick DG, Iczkowski KA, Amin MB, Discigil G, Osborne B. Malignant lymphoma involving the prostate: report of 62 cases. Cancer 1998; 83: 732-8.

6. Bell CR, Napier MP, Morgan RJ, Dick R, Jarmulowicz M, Jones AL Primary non-Hodgkin's lymphoma of the prostate gland: case report and review of the literature. Clin Oncol (R Coll Radiol) 1995; 7: 409-10.

7. Tomaru U, Ishikura H, Kon S, Kanda M, Harada H, Yoshiki T. Primary lymphoma of the prostate with features of low grade B-cell lymphoma of mucosa associated lymphoid tissue: a rare of urinary obstructions. J Urol 1999; 162: 496-7.

8. Oosterheert JJ, Budel LM, Vos P, Wittebol S. High levels of serum prostate-specific antigen due to PSA producing follicular nonHodgkin's lymphoma. Eur J Haematol 2007; 79: 155-8.

9. Rainwater LM, Barrett DM. Primary lymphoma of prostate: transrectal ultrasonic appearance. Urology 1990; 36: 522-5.

10. Terris MK, Freiha FS. Transrectal ultrasound appearance of hematolymphoid malignancies involving the prostate. Urology 1998; 51: 339-41.

11. Kerbl K, Pauer W. Primary non-Hodgkin lymphoma of prostate. Urology 1988; 32: 347-9.

12. Ballario R, Beltrami P, Cavalleri S, Ruggera L, Zorzi MG, Artibani W. An unusual pathological finding of chronic lymphocitic leukemia and adenocarcinoma of the prostate after transurethral resection for complete urinary retention: case report. BMC Cancer 2004; 4: 95.

13. Benekli M, Büyükașik Y, Haznedaroglu IC, Savaș MC, Ozcebe OI. Chronic lymphocytic leukemia presenting as acute urinary retention due to leukemic infiltration of the prostate. Ann Hematol 1996; 73: 143-4.

14. Alvarez CA, Rodriguez BI, Perez LA. Primary diffuse large B-cell lymphoma of the prostate in a young patient. Int Braz J Urol 2006; 32 64-5.
15. Sarris A, Dimopoulos M, Pugh W, Cabanillas F. Primary lymphoma of the prostate: good outcome with doxorubicin-based combination chemotherapy. J Urol 1995; 153: 1852-4.

16. Ben-Ezra J, Sheibani K, Kendrick FE, Winberg CD, Rappaport H. Angiotropic large-cell lymphoma of the prostate gland: an immunohistochemical study. Hum Pathol 1986; 17: 964-7.

17. Heresi GA, Wang J, Taichman R, Chirinos JA, Regalado JJ, Lichtstein DM, Rosenblatt JD. Expression of the chemokine receptor CCR7 in prostate cancer presenting with generalized lymphadenopathy: report of a case, review of the literature and analysis of chemokine receptor expression. Urol Oncol 2005; 23: 261-7.

18. Oster MW, Wolff M, Starrett S. Prostate cancer mimicking malignant lymphoma. Med Pediatr Oncol 1979; 7: 387-92.

19. Liel Y, Biderman A, Biran C, Katz M, Sacks M. Carcinoma of the prostate clinically and radiologically simulating malignant lymphoma. J Surg Oncol 1987; 35: 113-6.

20. Heaney JA, Delellis RA, Rudders RA. Non-Hodgkin lymphoma arising in lower urinary tract. Urology 1985; 25: 479-84.

\section{Address for correspondence}

\section{Dr. Peng Jiang}

Department of Urology, First Affiliated Hospital,

College of Medicine, Zhejiang University

No. 79 Qing Chun Road,

HangZhou City, 310029

ZheJiang Province, PR China

tel. 86-571-87236133

fax 86-571-87236594

e-mail: bellrin@163.com

Submitted: 10.11.2011

Accepted: $\quad 5.12 .2011$ 